\title{
Respon Penambahan Pupuk Hayati Terhadap Pertumbuhan dan Hasil Padi Sawah
}

\author{
Response of Biological Fertilizer Addition to Growth and Results of Rice Field \\ Jumakir Jumakir $^{*}$, Endrizal Endrizal ${ }^{1}$ \\ ${ }^{1}$ Balai Pengkajian Teknologi Pertanian Jambi, Jambi 36129 \\ ${ }^{*}$ Penulis untuk korespondensi: jumakirvilla@yahoo.co.id \\ (diterima 19 September 2019, disetujui 6 Oktober 2019)
}

Sitasi: Jumakir J, Endrizal E. 2019. Response of biological fertilizer addition to growth and results of rice field. Jurnal Lahan Suboptimal: Journal of Suboptimal Lands. 8(2): 173-180.

\begin{abstract}
The research objectives were to determine the effect or response of the addition of biological fertilizers to the growth and yield of rice, to determine the most effective type of biological fertilizer. This study was conducted in irrigated rice field of Sri Agung Village, Batang Asam sub District, West Tanjung Jabung District, Jambi Province in dry season 2016. The design was Randomized Block Design (RBD) with six treatments and three replications with $5 \mathrm{mx} 10 \mathrm{~m}$ plot area, implemented in a farmer area of $1200 \mathrm{~m}^{2}$. The results of the analysis based on the analysis of variance showed significant and unreal differences in growth and yield of rice. The addition of biological fertilizer provided higher growth and yields than without biological fertilizer. Provibio biofertilizer is the most effective biofertilizer that can provide the highest rice yield and the use of biofertilizer can save $50 \%$ recommended NPK fertilizer.
\end{abstract}

Keywords: rice, biological fertilizers and rice field

\begin{abstract}
ABSTRAK
Tujuan penelitian adalah untuk mengetahui pengaruh atau respon penambahan pupuk hayati terhadap pertumbuhan dan hasil padi, dan mengetahui jenis pupuk hayati yang paling efektif. Penelitian ini dilaksanakan di lahan sawah irigasi Desa Sri Agung Kecamatan Batang Asam Kabupaten Tanjung Jabung Barat Provinsi Jambi pada musim kemarau (MK) 2016. Rancangan yang digunakan adalah Rancangan Acak Kelompok (RAK) dengan tujuh perlakuan dan tiga ulangan dengan luas petakan $5 \mathrm{~m}$ x $10 \mathrm{~m}$, dilaksanakan di lahan petani seluas $1.200 \mathrm{~m}^{2}$. Hasil penelitian berdasarkan analisis sidik ragam menunjukkan perbedaan yang nyata dan tidak nyata terhadap pertumbuhan dan hasil padi. Penambahan pupuk hayati memberikan pertumbuhan dan hasil lebih tinggi dibanding tanpa pupuk hayati. Pupuk hayati Provibio merupakan pupuk hayati paling efektif mampu memberikan hasil padi tertinggi dan penggunaan pupuk hayati dapat menghemat penggunaan pupuk NPK rekomendasi 50 persen.
\end{abstract}

Kata kunci: padi, pupuk hayati dan lahan sawah 


\section{PENDAHULUAN}

Padi sebagai komoditas strategis dan menjadi andalan pemerintah untuk mencapai kedaulatan pangan (Jumakir, 2017). Produktivitas padi di lahan sawah irigasi yang diusahakan secara intensif akan mempengaruhi ketersediaan hara yang rendah (Suprijadi, 1999). Hasil penelitian mengindikasikan bahwa sebagian lahan pertanian intensif telah menurun produktivitasnya yaitu rendahnya kandungan C-organik kurang dari 2,0\%, bahkan kurang dari $1,0 \%$, padahal kandungan C-organik tanah untuk perolehan produktivitas optimal adalah lebih besar dari 2,5\% (Suriadikarta dan Simanungkalit, 2006).

Pemberian pupuk anorganik secara terus menerus dan tidak rasional menyebabkan hasil semakin menurun (Harsono et al., 2011). Menurut Wahyuningratri (2017) bahwa salah satu cara pemupukan yang dapat dilakukan agar tidak menimbulkan dapak negatif yang berlebihan terhadap lingkungan guna meningkatkan ketersediaan unsur hara bagi tanah dan tanaman melalui penambahan pupuk hayati. Penggunaan pupuk hayati yang banyak mengandung mikroorganisme penyubur tanah dan tanaman akan membantu mengembalikan kesuburan tanah secara berangsur, sehingga dalam jangka panjang akan meningkatkan ketersediaan hara tanah serta menyediakan bahan organik di dalam tanah. Pupuk hayati adalah mikroorganisme hidup yang ditambahkan ke dalam tanah dalam bentuk inokulan atau bentuk lain untuk memfasilitasi atau menyediakan hara tertentu bagi tanaman (Simanungkalit, 2006). Pupuk berbasis mikroba digolongkan ke dalam pupuk hayati karena merupakan suatu inokulan berbahan aktif organisme hidup yang berfungsi untuk menambat hara tertentu dalam tanah bagi tanaman (Hamasuti, 2012). Menurut Saraswati (2000) manfaat pupuk hayati terhadap tanaman melalui mekanisme: (a) perbaikkan penyediaan hara, (b) melindungi akar dari gangguan hama dan penyakit, (c) menstimulir sistem perakaran agar berkembang sempurna sehingga memperpanjang usia akar, (d) memacu mitosis jaringan meristem pada titik tumbuh pucuk, kuncup bunga, dan stolon, (e) penawar beberapa logam berat, (f) sebagai metabolit pengatur tumbuh, dan (g) sebagai bioaktifator. Penggunaan pupuk hayati pada tanaman padi, dapat meningkatkan jumlah akar, peningkatan jumlah anakan produktif (50\%), memperpanjang malai (8\%), jumlah gabah/malai meningkat $10-20 \%$ dan jumlah gabah isi/malai meningkat $14 \%$, secara keseluruhan meningkatkan hasil gabah sebesar 20-30\% (Saraswati, 2000). Selanjutya Jumakir et al. (2016), bahwa pemberian pupuk Urea, Phonska, dan Pupuk hayati meningkatkan hasil kedelai $19,61 \%-25,25 \%$ sedangkan pemberian pupuk Phonska, Dolomit, Pupuk kandang dan Pupuk hayati hasil kedelai meningkat 28,07\%-31,49\% dibanding pemberian pupuk Urea dan Phonska. Sehubungan dengan hal-hal tersebut di atas, demi tujuan perolehan produktivitas tanaman yang tinggi, menjaga kelestarian lahan dan kualitas lingkungan, serta penggunaan pupuk yang efisien tenaga/biaya, pengelolaan hara terpadu perlu dikembangkan dengan memadukan pemberian pupuk anorganik, pupuk organik, dan pupuk hayati. Penggunaan pupuk hayati dan organik dapat menambah hara tanah dan memperbaiki sifat fisik dan kimia tanah (Harsono et al., 2011). Pemberian pupuk anorganik dengan pupuk hayati secara nyata meningkatkan serapan $\mathrm{N}$ dan $\mathrm{P}$ pada tanaman padi (Sri Nuryani et al., 2010 dan Syam'un et al., 2012). Menurut Setiawati et al. (2016) bahwa pemberian pupuk NPK dengan pupuk hayati dapat menyediakan unsur $\mathrm{N}$ dan $\mathrm{P}$ tersedia bagi tanaman padi. Hasil penelitian Surono et al. (2012) bahwa penggunaan pupuk hayati + kompos 2,5 t/ha + 1/2 NPK rekomendasi memberikan hasil nyata lebih tinggi dibanding hanya pemberian kompos 5 t/ha dan pemupukan NPK rekomendasi. Tujuan penelitian adalah (1) untuk 
mengetahui pengaruh atau respons penambahan pupuk hayati terhadap pertumbuhan dan hasil padi, (2) mengetahui jenis pupuk hayati yang paling efektif.

\section{BAHAN DAN METODE}

Pengkajian ini dilaksanakan di lahan sawah irigasi Desa Sri Agung Kecamatan Batang Asam Kabupaten Tanjung Jabung Barat Provinsi Jambi pada musim kemarau (MK) 2016. Rancangan yang digunakan adalah Rancangan Acak Kelompok (RAK) dengan tujuh perlakuan dan tiga ulangan dengan luas petakan $5 \mathrm{~m}$ x $10 \mathrm{~m}$, dilaksanakan di lahan petani seluas 1.200 $\mathrm{m}^{2}$. Adapun ke tujuh perlakuan paket pemupukan padi tersebut adalah:

a. Urea $50 \mathrm{~kg} / \mathrm{ha}(\mathrm{BWD})+\mathrm{SP} 36100 \mathrm{~kg} / \mathrm{ha}$ $+\mathrm{KCl} 50 \mathrm{~kg} / \mathrm{ha}+$ Pukan $1000 \mathrm{~kg} / \mathrm{ha}$

b. Urea $150 \mathrm{~kg} / \mathrm{ha}+\mathrm{SP} 36100 \mathrm{~kg} / \mathrm{ha}+\mathrm{KCl}$ $50 \mathrm{~kg} / \mathrm{ha}$

c. Urea $150 \mathrm{~kg} / \mathrm{ha}+\mathrm{SP} 36100 \mathrm{~kg} / \mathrm{ha}+\mathrm{KCl}$ $50 \mathrm{~kg} / \mathrm{ha}+$ Pukan $2000 \mathrm{~kg} / \mathrm{ha}$

d. Urea $75 \mathrm{~kg} / \mathrm{ha}+\mathrm{SP} 3650 \mathrm{~kg} / \mathrm{ha}+\mathrm{KCl}$ $25 \mathrm{~kg} / \mathrm{ha}+$ Pukan $1000 \mathrm{~kg} / \mathrm{ha}+$ Agrimeth

e. Urea $75 \mathrm{~kg} / \mathrm{ha}+\mathrm{SP} 3650 \mathrm{~kg} / \mathrm{ha}+\mathrm{KCl}$ $25 \mathrm{~kg} / \mathrm{ha}+$ Pukan $1000 \mathrm{~kg} / \mathrm{ha}+$ Biovam

f. Urea $75 \mathrm{~kg} / \mathrm{ha}+\mathrm{SP} 3650 \mathrm{~kg} / \mathrm{ha}+\mathrm{KCl} 25$ $\mathrm{kg} / \mathrm{ha}+$ Pukan $1000 \mathrm{~kg} / \mathrm{ha}+$ Provibio

g. Urea $75 \mathrm{~kg} / \mathrm{ha}+\mathrm{SP} 3650 \mathrm{~kg} / \mathrm{ha}+\mathrm{KCl}$ $25 \mathrm{~kg} / \mathrm{ha}+$ Pukan $1000 \mathrm{~kg} / \mathrm{ha}+$ Nutrifarm

Varietas padi yang digunakan adalah Inpari 30 dan sistem tanam jajar legowo 4: $1(12,5 \times 25 \times 50) \mathrm{cm}$. Pengaturan jarak tanam yang teratur untuk memudahkan dalam pemupukan, pengendalian gulma dan pengendalian OPT. Pemupukan dilakukan sesuai dengan perlakuan masing-masing. Pemberian pupuk Urea, SP 36 dan $\mathrm{KCl}$ diberikan pada umur 7-10 HST, dilakukan secara sebar. Pemberian pupuk Urea ke dua dilakukan 30 HST dan sesuai perlakuan (BWD). Takaran pupuk hayati dan cara aplikasi dilakukan sesuai dengan SOP masing-masing produk pupuk hayati :
1). Biovam (LIPI) yaitu benih padi direndam ke dalam ember, kemudian ditiriskan. Benih padi dicampur dengan Biovam (5 kg per hektar) dengan cara mencampur benih padi kedalam bubur Biovam + yang telah disiapkan dalam suatu wadah. Bubur Biovam disiapkan dengan mencapur Biovam + dengan sedikit air agar merata menyerupai bubur. Benih padi yang sudah dilumuri dengan Biovam selanjutnya bisa disemai seperti umumnya petani menyemai padi.

2). Provibio (IPB) yaitu benih padi direndam ke dalam ember, kemudian ditiriskan. Benih padi dicampur dengan Provibo (1 L/ha) dan disemai, kemudian pemberian provibio dilakukan dengan penyemprotan pada tanaman padi umur 14 , 45 dan 60 HST dengan takaran masingmasing $2 \mathrm{~L} / \mathrm{ha}$.

3) Agrimeth (Balitbangtan) yaitu benih padi direndam ke dalam ember, kemudian ditiriskan. Inokulan ditaburkan ke dalam benih (500 gr/25 kg benih/ha) diaduk sampai merata. Upayakan benih yang telah tercampur dengan inokulan Agrimeth tidak kena cahaya matahari langsung agar tidak mematikan mikroba yang telah melekat pada benih, kemudian benih padi disemai dan ditutup dengan tanah/pupuk organik. Agrimeth

mengandung bakteri filosfer Methylobact erium, sp. penghasil fitohormon.

4). Nutrifarm adalah pupuk pelengkap cair organik yang disemprotkan ke tanaman padi dengan takaran $1 \mathrm{~L} / \mathrm{ha}$. Penyemprotan dilakukan pada tanaman padi saat primordia dan keluar bunga.

Peubah yang diamati adalah persentase tumbuh, keragaan tanaman, tinggi tanaman saat panen, panjang malai, jumlah anakan produktif, jumlah gabah isi, jumlah gabah hampa, dan hasil (t/ha).

Jenis data yang diamati terdiri dari :

1. Tinggi tanaman $(\mathrm{cm})$, pengambilan data tinggi tanaman dapat dilakukan apabila telah masak fisiologis sampai saat akan panen. Tinggi tanaman diukur dari permukaan tanah sampai malai 
terpanjang pada tanaman sampel yang diamati pada saat panen;

2. Jumlah anakan produktif (batang) dihitung masing-masing sampel tanaman;

3. Panjang malai $(\mathrm{cm})$ dihitung dengan mengukur dari leher malai sampai ujung malai;

4. Jumlah gabah isi per malai (biji). Data jumlah gabah isi per malai didapat dengan menghitung seluruh gabah isi pada tanaman sampel yang diamati pada saat panen;

5. Jumlah gabah hampa per malai (biji). gabah yang tidak menghasilkan biji dengan sempurna digolongkan kedalam gabah yang tidak bernas atau hampa pada tanaman sampel yang diamati pada saat panen;

6. Hasil per plot (4 $\mathrm{m} \times 5 \mathrm{~m})(\mathrm{kg})$, dihitung dengan menimbang semua hasil yang didapat dari plot-plot perlakuan.

Analisis Statistik :

Model matematik untuk pengkajian ini adalah sebagai berikut :
$Y i j=\mu+\alpha i+\beta j+\sum i j$

Dimana :

kelompok

$$
\mu=\text { Harga rata-rata harapan }
$$

$\alpha \mathrm{i}=$ Pengaruh ulangan atau

$\beta \mathrm{j}=$ Pengaruh perlakuan varietas

$\sum \mathrm{ij}=$ Kesalahan percobaan

Data pertumbuhan dan hasil akan dianalisis, menggunakan analysis of varians (ANOVA) dengan uji lanjut DMRT. Menurut Gomez and Gomez (1976) (Tabel $1)$.

Perbedaan dari masing-masing perlakuan dapat diketahui melalui perbandingan antara $\mathrm{F}$ hitung dan $\mathrm{F}$ tabel. Perlakuan tersebut akan menunjukkan berbeda nyata bila $\mathrm{F}$ hitung lebih besar dari $\mathrm{F}$ tabel pada taraf uji 5 persen dan menunjukkan perbedaan sangat nyata bila $F$ hitung lebih besar dari $\mathrm{F}$ tabel pada taraf uji 1 persen serta tidak berbeda nyata bila nilai $\mathrm{F}$ hitung lebih kecil dari $\mathrm{F}$ tabel pada taraf uji 5 persen.

Tabel 1. Daftar sidik ragam

\begin{tabular}{lrcccc}
\hline $\begin{array}{l}\text { Sumber keragaman } \\
\text { (SK) }\end{array}$ & $\begin{array}{c}\text { Derajat Bebas } \\
(\mathrm{DB})\end{array}$ & $\begin{array}{c}\text { Jumlah } \\
\text { Kuadrat (JK) }\end{array}$ & $\begin{array}{c}\text { Kuadrat Tengah } \\
(\mathrm{KT})\end{array}$ & \multirow{2}{*}{ F hit } & \multicolumn{2}{c}{ F tabel } \\
\hline Kelompok & $(\mathrm{r}-1)$ & $\mathrm{JKr}$ & $\mathrm{JKr} / \mathrm{r}-1$ & $\mathrm{KTr} / \mathrm{Kta}$ & \\
Perlakuan & $(\mathrm{t}-1)$ & $\mathrm{JKt}$ & $\mathrm{JKt} / \mathrm{r}-1$ & $\mathrm{KTt} / \mathrm{Kta}$ & \\
Acak & $(\mathrm{r}-1)(\mathrm{t}-1)$ & $\mathrm{JKa}$ & $\mathrm{Jka} /(\mathrm{r}-1)(\mathrm{t}-1)$ & & \\
Total & $(\mathrm{rt}-1)$ & & & & \\
\hline
\end{tabular}

\section{HASIL DAN PEMBAHASAN}

Hasil analisis sidik ragam menunjukkan bahwa respon penambahan pupuk hayati berpengaruh sangat nyata dan nyata terhadap tinggi tanaman, jumlah anakan produktif, jumlah gabah isi, dan panjang malai serta tidak berbeda nyata terhadap jumlah gabah hampa dan hasil (Tabel 2).

\section{Pertumbuhan Tanaman Padi}

Persentase tumbuh tanaman padi yang diujicobakan mencapai $90 \%$, tingginya persentase tumbuh ini disebabkan oleh kualitas benih bermutu, dan ketersediaan hara dengan adanya perlakuan pemupukan. Keragaan tanaman padi menunjukkan pertumbuhan yang cukup beragam sesuai dengan perlakuan pemupukan, tinggi tanaman dan jumlah anakan menunjukkan berbeda nyata antar perlakuan (Tabel 3).

Dari tujuh perlakuan yang diuji menunjukkan pada perlakuan pemupukan Urea $150 \mathrm{~kg} / \mathrm{ha}+\mathrm{SP} 36100 \mathrm{~kg} / \mathrm{ha}+\mathrm{KCl}$ $50 \mathrm{~kg} / \mathrm{ha}+$ Pukan $2000 \mathrm{~kg} / \mathrm{ha}$ (C) dan perlakuan pemupukan Urea $75 \mathrm{~kg} / \mathrm{ha}+\mathrm{SP}$ $3650 \mathrm{~kg} / \mathrm{ha}+\mathrm{KCl} 25 \mathrm{~kg} / \mathrm{ha}+$ Pukan $1000 \mathrm{~kg} / \mathrm{ha}+$ Provibio (F) terlihat pertumbuhan tanaman baik dan sangat baik, sedangkan perlakuan lainnya menunjukkan pertumbuhan yang baik. Hal ini menunjukkan bahwa tanaman padi membutuhkan pupuk yang dapat diaplikasikan ke tanah maupun ke tanamannya. Dari Tabel 3 diatas terlihat 
bahwa tinggi tanaman padi dan jumlah anakan produktif cukup beragam. Tinggi tanaman berkisar $87,13 \mathrm{~cm}$ sampai 97,40 $\mathrm{cm}$. Tinggi tanaman merupakan salah satu kriteria pertumbuhan tanaman padi, tetapi pertumbuhan yang tinggi belum menjamin tingkat produktivitasnya. Tinggi tanaman mempunyai pengaruh yang besar terhadap hubungan antara panjang malai dengan hasil (Kamandanu, et al. 2003). Jumlah anakan produktif dan panjang malai masing-masing perlakuan cukup beragam, pemupukan Urea $150 \mathrm{~kg} / \mathrm{ha}+$ SP 36100 $\mathrm{kg} / \mathrm{ha}+\mathrm{KCl} 50 \mathrm{~kg} / \mathrm{ha}+$ Pukan $2000 \mathrm{~kg} / \mathrm{ha}$ (C) memberikan jumlah anakan lebih banyak dan malainya lebih panjang dibanding perlakuan lainnya, namun tidak berbeda nyata dengan perlakuan Urea 75 $\mathrm{kg} / \mathrm{ha}+\mathrm{SP} 3650 \mathrm{~kg} / \mathrm{ha}+\mathrm{KCl} 25 \mathrm{~kg} / \mathrm{ha}$ + Pukan 1000 kg/ha + Provibio (F). Hal ini menunjukkan bahwa pupuk kandang dikombinasikan dengan pupuk kimia dan pupuk hayati dapat meningkatkan pertumbuhan tanaman. Menurut Sutanto
(2006) bahwa pupuk kandang dapat memperbaiki 1) sifat fisik tanah, tanah menjadi gembur dan aerasi tanah menjadi lebih baik. 2) sifat kimia tanah, meningkatnya kapasitas tukar kation dan meningkatnya ketersediaan hara. 3) sifat biologi tanah, meningkatnya populasi mikroorganisme tanah yang berperan penting terhadap pertumbuhan tanaman. Penggunaan pupuk hayati pada tanaman padi dapat meningkatkan jumlah anakan produktif $(50 \%)$ dan memperpanjang malai (8\%) (Saraswati, 2000). Jumlah anakan produktif merupakan faktor pendukung utama untuk potensi hasil dan salah satu parameter yang berpengaruh langsung terhadap hasil (Siregar et al, 1998 dan Kamandanu et al. 2003). Pemberian pupuk hayati berpengaruh nyata terhadap sidik ragam tinggi tanaman, jumlah anakan maksimum, anakan produktif, persentase gabah isi, jumlah gabah permalai per rumpun, bobot gabah 1000 bulir, dan berat gabah per rumpun (Didit et al., 2013).

Tabel 2. Analisis sidik ragam respon penambahan pupuk hayati pada tanaman padi di lahan sawah irigasi Provinsi Jambi

\begin{tabular}{lrr}
\hline Peubah yang Diamati & F hitung & KK $(\%)$ \\
\hline Tinggi Tanaman & $7,14^{\mathrm{xx}}$ & 2,68 \\
Jumlah Anakan Produktif & $16,09^{\mathrm{xx}}$ & 17,84 \\
Panjang Malai & $3,17^{\mathrm{x}}$ & 14,98 \\
Jumlah Gabah Isi & $4,83^{\mathrm{xx}}$ & 5,73 \\
Jumlah Gabah Hampa & $2,80^{\mathrm{ns}}$ & 15,48 \\
Hasil & $2,11^{\mathrm{ns}}$ & 4,01 \\
\hline F tabel 0,05 & 3,00 & 4,82 \\
F tabel 0,01 & & 4 \\
\hline
\end{tabular}

Tabel 3. Rata-rata persentase tumbuh, keragaan tanaman, tinggi tanaman dan jumlah anakan produktif padi di lahan sawah irigasi

\begin{tabular}{lcccc}
\hline $\begin{array}{c}\text { Perlakuan } \\
\text { Persentase Tumbuh } \\
(\%)\end{array}$ & Keragaan Tanaman & Tinggi Tanaman $(\mathrm{cm})$ & $\begin{array}{c}\text { Jumlah Anakan } \\
\text { Produktif }\end{array}$ \\
\hline A & 90 & 3 & $91,20^{\mathrm{ab}}$ & $13,27^{\mathrm{ab}}$ \\
B & 90 & 3 & $87,13^{\mathrm{a}}$ & $13,20^{\mathrm{a}}$ \\
C & 90 & $3-1$ & $97,27^{\mathrm{c}}$ & $17,53^{\mathrm{d}}$ \\
$\mathrm{D}$ & 90 & 3 & $95,27^{\mathrm{c}}$ & $13,20^{\mathrm{a}}$ \\
E & 90 & 3 & $94,20^{\mathrm{bc}}$ & $15,40^{\mathrm{bc}}$ \\
F & 90 & $3-1$ & $97,40^{\mathrm{c}}$ & $16,53^{\mathrm{cd}}$ \\
G & 90 & 3 & $97,40^{\mathrm{c}}$ & $14,47^{\mathrm{b}}$ \\
\hline
\end{tabular}

Keterangan: Angka-angka yang diikuti oleh huruf yang sama tidak berbeda nyata pada uji DMRT taraf 5\% Keragaan tanaman (score) $: 1=$ Pertumbuhan merata dan sangat baik, 3 = Pertumbuhan merata dan baik 


\section{Hasil dan Komponen Hasil}

Hasil analisis statistik menunjukkan hasil dan komponen hasil berbeda nyata dan tidak nyata antar perlakuan. Rata-rata panjang malai, jumlah gabah isi dan jumlah gabah hampa tergantung pada perlakuan yang mempengaruhinya. Panjang malai berkisar 22,93 cm (Urea $150 \mathrm{~kg} / \mathrm{ha}+\mathrm{SP} 36$ $150 \mathrm{~kg} / \mathrm{ha}+\mathrm{KCl} 50 \mathrm{~kg} / \mathrm{ha}$ ) (B) sampai $25,40 \mathrm{~cm}$ (Urea $150 \mathrm{~kg} / \mathrm{ha}+$ SP 36100 $\mathrm{kg} / \mathrm{ha}+\mathrm{KCl} 50 \mathrm{~kg} / \mathrm{ha}+$ Pukan $2000 \mathrm{~kg} / \mathrm{ha}$ ) (C). Jumlah gabah isi per malai lebih dari 100 butir terdapat pada pemupukan Urea 50 $\mathrm{kg} / \mathrm{ha}(\mathrm{BWD})+\mathrm{SP} 36100 \mathrm{~kg} / \mathrm{ha}+\mathrm{KCl} 50$ $\mathrm{kg} / \mathrm{ha}+$ Pukan $1000 \mathrm{~kg} / \mathrm{ha}$ (A), pemupukan Urea $150 \mathrm{~kg} / \mathrm{ha}+\mathrm{SP} 36100 \mathrm{~kg} / \mathrm{ha}+$ $\mathrm{KCl} 50 \mathrm{~kg} / \mathrm{ha}+$ Pukan $2000 \mathrm{~kg} / \mathrm{ha}$ (C) dan pemupukan Urea $75 \mathrm{~kg} / \mathrm{ha}+\mathrm{SP} 3650$ $\mathrm{kg} / \mathrm{ha}+\mathrm{KCl} 25 \mathrm{~kg} / \mathrm{ha}+$ Pukan $1000 \mathrm{~kg} / \mathrm{ha}$ + Provibio (F). Jumlah gabah hampa terendah pada pemupukan Urea $150 \mathrm{~kg} / \mathrm{ha}$ + SP $36100 \mathrm{~kg} / \mathrm{ha}+\mathrm{KCl} 50 \mathrm{~kg} / \mathrm{ha}+$ Pukan $2000 \mathrm{~kg} / \mathrm{ha}$ dan Urea $75 \mathrm{~kg} / \mathrm{ha}+\mathrm{SP}$ $3650 \mathrm{~kg} / \mathrm{ha}+\mathrm{KCl} 25 \mathrm{~kg} / \mathrm{ha}+$ Pukan $1000 \mathrm{~kg} / \mathrm{ha}+$ Provibio (F).

Tabel 4. Rata-rata panjang malai, jumlah gabah isi, jumlah gabah hampa dan hasil tanaman padi di lahan sawah irigasi

\begin{tabular}{ccccc}
\hline Perlakuan & Panjang Malai (cm) & $\begin{array}{c}\text { Jumlah } \\
\text { Gabah Isi/Malai }\end{array}$ & $\begin{array}{c}\text { Jumlah } \\
\text { Gabah Hampa/Malai }\end{array}$ & $\begin{array}{c}\text { Hasil } \\
(\mathrm{t} / \mathrm{ha})\end{array}$ \\
\hline $\mathrm{A}$ & $24,27^{\mathrm{b}}$ & $90,67^{\mathrm{a}}$ & $15,53^{\mathrm{b}}$ & $6,06^{\mathrm{a}}$ \\
$\mathrm{B}$ & $22,93^{\mathrm{a}}$ & $89,67^{\mathrm{a}}$ & $20,53^{\mathrm{c}}$ & $5,90^{\mathrm{a}}$ \\
$\mathrm{C}$ & $25,40^{\mathrm{b}}$ & $104,33^{\mathrm{bc}}$ & $9,53^{\mathrm{ab}}$ & $6,57^{\mathrm{ab}}$ \\
$\mathrm{D}$ & $24,00^{\mathrm{a}}$ & $102,20^{\mathrm{b}}$ & $18,07^{\mathrm{bc}}$ & $6,30^{\mathrm{a}}$ \\
$\mathrm{E}$ & $23,50^{\mathrm{a}}$ & $96,07^{\mathrm{ab}}$ & $15,47^{\mathrm{b}}$ & $6,15^{\mathrm{a}}$ \\
$\mathrm{F}$ & $24,20^{\mathrm{ab}}$ & $106,27^{\mathrm{c}}$ & $4,07^{\mathrm{a}}$ & $6,96^{\mathrm{b}}$ \\
G & $24,20^{\mathrm{ab}}$ & $90,67^{\mathrm{a}}$ & $17,47^{\mathrm{b}}$ & $6,10^{\mathrm{a}}$ \\
\hline Keterangan: Angka-angka yang diikuti oleh huruf yang sama tidak berbeda nyata pada uji DMRT taraf 5\%
\end{tabular}

Dari Tabel 4 terlihat bahwa hasil per hektar padi tertinggi dijumpai pada pemupukan Urea $75 \mathrm{~kg} / \mathrm{ha}+$ SP 3650 $\mathrm{kg} / \mathrm{ha}+\mathrm{KCl} 25 \mathrm{~kg} / \mathrm{ha}+$ Pukan $1000 \mathrm{~kg} / \mathrm{ha}$ + Provibio sebesar 6,96 t/ha (G), sedangkan yang terendah diperoleh dengan pemupukan Urea $150 \mathrm{~kg} / \mathrm{ha}+\mathrm{SP} 36150 \mathrm{~kg} / \mathrm{ha}+\mathrm{KCl}$ $50 \mathrm{~kg} / \mathrm{ha}$ yaitu $5,90 \mathrm{t} / \mathrm{ha}$ (B). Hal ini menunjukkan bahwa kombinasi pemupukan Urea, SP 36, $\mathrm{KCl}$, pukan dan pupuk hayati sangat dibutuhkan tanaman padi. Syam (2009) mengatakan bahwa penggunaan bahan organik dari sisa tanaman dan pupuk kandang dikombinasikan dengan pupuk kimia dapat mendukung upaya peningkatan produksi pangan nasional. Selanjutnya Harsono et al., (2011) bahwa penggunaan pupuk hayati dan organik dapat menambah hara tanah dan memperbaiki sifat fisik dan kimia tanah. Pupuk hayati dikombinasikan dengan pupuk NPK secara nyata dapat meningkatkan produktivitas padi sawah maupun padi gogo (Fadiluddin, 2009 dan Aryanto et al., 2015). Penggunaan pupuk hayati yang sesuai dengan kondisi tanah, selain merupakan alternatif yang murah untuk meningkatkan kesuburan tanah juga dapat meningkatkan efisiensi pemupukan dan produktivitas tanaman. Hasil penelitian Aryanto et al. (2015) bahwa perlakuan pupuk hayati dapat mengurangi dosis pupuk anorganik $50 \%$, dimana mikroba dalam pupuk hayati mampu menurunkan dosis pupuk anorganik hingga 50\% pada tanaman pangan (Pangaribuan et al., 2012; Indriani dan Asniah, 2013). Selanjutnya hasil penelitian Supriyo et al. (2014) bahwa aplikasi pupuk hayati yang dikombinasikan dengan setengah rekomendasi NPK memberikan hasil yang sebanding dengan pemupukan NPK rekomendasi artinya penggunaan pupuk hayati dapat menghemat penggunaan pupuk NPK rekomendasi sekitar 50 persen (Aryanto et al., 2015). Tanaman yang tumbuh baik mampu menyerap hara dalam jumlah banyak sehingga pada lingkungan tumbuh yang cukup hara, akan berpengaruh terhadap peningkatan aktivitas fotosintesa tanaman, dan berakibat pada pertumbuhan dan 
komponen hasil tanaman yang meningkat (Yoshida, 1981).

\section{KESIMPULAN}

Penambahan pupuk hayati memberikan pertumbuhan dan hasil lebih tinggi dibanding tanpa pemberian pupuk hayati. Pupuk hayati Provibio merupakan pupuk hayati paling efektif mampu memberikan hasil padi tertinggi dan penggunaan pupuk hayati dapat menghemat penggunaan pupuk NPK rekomendasi 50 persen.

\section{UCAPAN TERIMA KASIH}

Penulis mengucapkan terima kasih kepada BPTP Jambi Badan Penelitian dan Pengembangan Pertanian Kementerian Pertanian yang telah membiayai penelitian ini.

\section{DAFTAR PUSTAKA}

Aryanto A, Triadiati, Sugiyanta. 2015. Pertumbuhan dan produkasi padi sawah dan gogo dengan pemberian pupuk hayati berbasis bakteri pemacu tumbuh di tanah masam. Jurnal Ilmu Pertanian Indonesia (JIPI). 20(3): 229-235.

Didit NY, Setia, Kiswan MH. 2013. Pengaruh pupuk hayati terhadap pertumbuhan dan hasil padi sawah dengan metode SRI pada tanah Alluvial. Jurnal Sains Mahasiswa Pertanian. 2(1): 6-17.

Fadiluddin M. 2009. Efektivitas formula pupuk hayati dalam memacu serapan hara, produksi dan kualitas hasil jagung dan padi gogo dilapang. Tesis IPB Bogor.

Hamasuti H. 2012. Peran mikroorganisme Azotobacter sp, Pseudomanas sp, Aspergillus niger pada pembuatan kompos limbah sludge industri pengolahan susu. Jurnal Teknik Pomits. 1(1): $1-5$.

Harsono A, Subandi, Suryantini. 2011. Formulasi pupuk hayati dan organic untuk meningkatkan produktivitas aneka kacang 20\%. ubi $40 \%$ menghemat pupuk kimia 50\%. Laporan Hasil Penelitian Tahun 2010. Balitkabi. $53 \mathrm{Hlm}$.

Indriani L, Asniah. 2013. Aplikasi pupuk organik dan pupuk hayati terhadap pertumbuhan bibit kakao. Agriplus. 23(3): 208-213.

Jumakir, Endrizal, Suyamto. 2016. Uji beberapa paket pemupukan dan dolomit terhadap hasil kedelai di lahan rawa pasang surut Provinsi Jambi. Jurnal Lahan Sub Optimal. 5(1): 86-94.

Jumakir. 2017. Budidaya Padi Varietas Unggul Lahan Rawa. IAARD Press. Jakarta. 136 hal.

Kamandanu AANB, Rubiyo, Darajat AA. 2003. Keragaan galur harapan padi sawah didua lokasi di Bali. Di dalam: Suprihatno, B.et al. (2003). Kebijakan Perberasan dan Inovasi Teknologi Padi (Buku 2). Pusat Penelitian Tanaman Pangan.

Pangaribuan DH, Yasir M, Utami NK. 2012. Dampak bokashi kotoran ternak dalam pemakaian pupuk anorganik pada budidaya tanaman tomat. Jurnal Agronomi Indonesia. 40(3): 204-210.

Saraswati R. 2000. Peranan pupuk hayati dalam peningkatan produktivitas pangan. P. 46-54: Suwarno, et al. (Eds.): Tonggak Kemajuan Teknologi Produksi Tanaman Pangan: Paket dan komponen Teknologi Produksi Padi. Simposium Penelitian Tanaman Pangan IV, Bogor, 22-24 November 1999. Pusat Penelitian dan Pengembangan Tanaman Pangan, Badan Penelitian dan Pengembangan Pertanian.

Setiawati MR, Sofyan ET, Mutaqin Z. 2016. Pengaruh pupuk hayati padat terhadap serapan $\mathrm{N}$ dan $\mathrm{P}$ tanaman, komponen hasil dan hasil padi sawah. Jurnal Agroekotek. 8(2): 120-130.

Simanungkalit. 2006. Aplikasi pupuk hayati dan kimia: Suatu pendekatan terpadu. $J$ Agronomi Bioteknologi. 4(2): 56-61.

Siregar H, Endang S, Soewito. 1998. Analisis beberapa sifat galur padi sawah dua musim tanam di Pusakanegara. 
Penelitian Pertanian tanaman Pangan:17(1): 33-34

Sri Nuryani HU, Haji M, Widya N. 2010. Serapan hara N, P, K pada tanaman padi dengan berbagai lama penggunaan pupuk organik pada Vertisol Sragen. Jurnal Ilmu Tanah dan Lingkungan. 10(1):1-13.

Suprijadi. 1999. Di dalam Sarlan Abdulrachman dan Supriadi. 2000. Pemanfaatan jerami untuk memperbaiki kesuburan tanah Aluvial. Simposium Penelitian Tanaman Pangan IV. Bogor. 22-24 Nopemeber 1999. Puslitbangtan. Badan Litbangtan.

Supriyo A, Minarsih S, Prayudi B. 2014. Efektifitas pemberian pupuk hayati terhadap pertumbuhan dan hasil padi gogo pada tanah kering. Agriteh. 16(1):1-12

Suriadikarta DA, Simanungkalit RDM. 2006. Pendahuluan, p.1-10. Di dalam: Simanungkalit et al. (Ed.). Pupuk organik dan pupuk hayati. Balai Besar Litbang Sumberdaya Lahan Pertanian.

Surono, Santoso E, Yuniarti E. 2012. Penggunaan pupuk hayati, organik dan anorganik untuk meningkatkan efisiensi pupuk dan produktvitas padi pada tiga sistem budidaya padi sawah. Widyariset. 15(2): 301-311.

Sutanto R. 2006. Penerapan Pertanian Organik. Kanisius. Yogyakarta.

Syam M. 2009. Padi organik dan tuntutan peningkatan produksi beras. Iptek Tanaman Pangan. 3(1): April 2008. Puslitbangtan. Badan Litbang Pertanian. Bogor.

Syam'un E, Kaimuddi, Dachla A. 2012. Pertumbuhan vegetatif dan serapan $\mathrm{N}$ tanaman yang diaplikasikan pupuk $\mathrm{N}$ anorganik dan mikroba penambat $\mathrm{N}$ non simbiotik. Jurnal Agrivigor. 11(2):251261.

Wahyuningratri A, Aini N, Heddy S. 2017. Pengaruh kosentrasi dan frekuensi pemberian pupuk hayati terhadap pertumbuhan dan hasil cabai besar (Capsicum annum L). Jurnal Produksi Tanaman. 5(1): 84-91.

Yoshida S.1981. Fundamental of Rice Crop Science. International Rice Research Institut. Manila. 